\title{
Integrando saberes: reflexão sobre o currículo integrado da Educação Profissional Técnica de nível médio no Instituto Federal de Brasília
}

\author{
Tiago Borges dos Santos ${ }^{1}$ \\ ${ }^{1}$ Instituto Federal de Brasília \\ tiago.santos@ifb.edu.br
}

Artigo submetido em 23/01/2012 e aceito em 17/05/2012.

\section{RESUMO}

O objetivo geral deste ensaio é subsidiar reflexões e debates sobre a elaboração do currículo da educação profissional técnica de nível médio articulada, na forma integrada, com 0 ensino médio, no âmbito do Instituto Federal de Brasília. Entre as finalidades específicas do texto, elencam-se: a compilação da legislação sobre educação profissional e ensino médio; a síntese histórica da relação entre ensino médio e ensino técnico no Brasil República; o estabelecimento de parâmetros para a implantação do currículo integrado; a proposição de componentes curriculares para parte diversificada; e, por fim, a elaboração de uma proposta curricular integrada a ser desenvolvida pela instituição.

A metodologia adotada compreendeu uma abordagem histórica, pedagógica e técnica do tema, conjugada ao cotejamento da legislação educacional. Como resultado, pode-se elencar a definição da carga horária dos cursos e a sugestão de uma referência curricular a ser adequada e aperfeiçoada, de acordo com a realidade de cada Campus do Instituto Federal de Brasília.

PALAVRAS-CHAVE: currículo integrado; educação profissional; ensino médio.

\section{Integrating knowledge: refletion on the integrated curriculum of vocational and technical schools at the Federal Institute of Brasília}

\section{ABSTRACT}

The main objective of this essay is to promote reflection and discussion on the development of the curriculum of Vocational and Technical Schools which are integrated with High School courses in the Federal Institute of Brasília. Among the specific goals of this text we can list: a compilation of the legislation about Professional Education and Secondary Education, a historical overview of the relation between High School and Professional Education during the the proposition of school subjects for the diversified part of the school curriculum, and finally, the proposal of an integrated curriculum to be developed by the institution.

The methodology adopted was based on a historical, pedagogical and technical approach, which was also related to the legislation concerning national education. As a result, we propose the course workload and suggest a curriculum reference which might be adapted to the reality of each campus of the Federal Institute of Brasília. 


\section{SANTOS (2012)}

Republican era in Brazil and the guidelines which supported the implementation of the integrated curriculum,

KEY-WORDS: integrated curriculum, professional education; high school. 


\section{INTEGRANDO SABERES: REFLEXÃO SOBRE O CURRÍCULO INTEGRADO DA EDUCAÇÃO PROFISSIONAL TÉCNICA DE NÍVEL MÉDIO NO INSTITUTO FEDERAL DE BRASÍLIA}

\section{INTRODUÇÃO}

Esse ensaio foi engendrado pela necessidade do Instituto Federal de Educação, Ciência e Tecnologia de Brasília em ofertar cursos de educação profissional técnica de nível médio na forma integrada. O currículo do curso integrado pressupõe a síntese entre a formação propedêutica do ensino médio e a habilitação profissional proporcionada pelo ensino técnico. O objetivo do texto é subsidiar a elaboração dos currículos integrados nos campi, por meio da apresentação de uma proposta de integração dos conteúdos técnicos e propedêuticos. Mas, antes de realizar uma abordagem técnica da questão, cabe uma breve digressão histórica sobre as relações estabelecidas entre o ensino secundário/2ํㅜㄴ grau/ ensino médio e a formação profissional.

\section{No túnel do tempo}

Nos tantos começos possíveis para o percurso histórico da integração entre ensino médio e educação profissional, seleciono o contexto da Era Vargas, situado entre 1930 e 1945, e caracterizado, entre outros aspectos, pela fundação do Ministério da Educação e Saúde, que centralizou as políticas públicas educacionais; pelas Leis Orgânicas do Ensino; pelo Manifesto dos Pioneiros da Educação; pelo estímulo à industrialização; pela Consolidação das Leis Trabalhistas; pela substituição das Escolas de Aprendizes e Artífices por Escolas Industriais Técnicas e pelo início do Sistema S.

O Estado Novo, período político que significou a acentuação da ditadura varguista, foi legitimado pelos princípios da Constituição de 1937. O artigo 129 da referida Carta Magna estabeleceu: "O ensino pré-vocacional e profissional destinado às classes menos favorecidas" (BRASIL, 1937). Como afirma Santos (2008), tal dispositivo legal institucionalizava a dualidade escolar no Brasil: enquanto a elite cursava o ensino secundário visando continuar os estudos no ensino superior, as classes populares ficavam fadadas à terminalidade do ensino profissional. A desvalorização do trabalho manual e sua associação com a parcela mais pobre da população no Brasil é uma das heranças perversas legadas por mais de três séculos de escravidão.

No campo educacional, intelectuais como Anísio Teixeira, Afrânio Peixoto e Fernando de Azevedo idealizaram o Manifesto dos Pioneiros da Educação Nova que propagava no país as ideias da pedagogia escolanovista, cujo processo educacional era focado no aluno, percebido como sujeito da sua própria aprendizagem, em contraposição aos paradigmas da pedagogia tradicional vigentes à época.

Outro momento histórico relevante para refletir sobre a questão é a publicação da Lei $5.692 / 71$, durante o Regime Militar. Essa lei, que reformou a educação de $1^{\circ}$ e $2^{\circ}$ graus, definiu a obrigatoriedade da integração entre o ensino profissional e segundo grau. 0 que poderia representar um avanço na educação do país significou o aprofundamento da dicotomia escolar, pois enquanto as escolas públicas estavam sem recursos e sem estrutura para oferecer cursos profissionalizantes de qualidade, as escolas particulares focaram na preparação para o vestibular, incluindo poucas disciplinas técnicas em seu 


\section{SANTOS (2012)}

currículo, apenas para formalidade do cumprimento da lei. Já as escolas técnicas de boa qualidade, que existiam antes da lei, foram rebaixadas ao nível das escolas secundárias comuns.

$\mathrm{Na}$ conjuntura da ditadura militar, a medida de conferir caráter profissionalizante ao ensino secundário não tinha como objetivo apenas desenvolver o país ou fornecer mão de obra para indústria, mas, também, diminuir a demanda para o ensino superior, cujas manifestações estudantis incomodavam o governo.

Nesse período predominaram as práticas pedagógicas com viés tecnicista, que objetivavam modelar o comportamento por meio de técnicas específicas. O tecnicismo era ancorado no behaviorismo, na neutralidade científica, na racionalidade, na eficiência e na produtividade (SAVIANI, 2008). Assim, a formação profissional oferecida pelas instituições escolares fundamentava-se na concepção de produção fordista, na qual o técnico não participava do planejamento e era treinado para realizar atividades operacionais repetitivas e padronizadas para produção em série.

A profissionalização compulsória do segundo grau não teve bons resultados e foi revogada onze anos depois, pela Lei 7.044/82.

Não obstante a atual Lei de Diretrizes e Bases da Educação Nacional, vigente desde 1996, estabeleça que a educação escolar deve vincular-se ao mundo do trabalho (Art. $\left.1^{\circ}\right)$, que a qualificação para o trabalho é uma finalidade da educação nacional (Art. $2^{\circ}$ ); que a educação básica deve fornecer meios para o educando progredir no trabalho (Art. $22^{\circ}$ ); que é diretriz curricular básica a orientação para o trabalho (Art. 27); e que é finalidade do ensino médio a preparação para o trabalho; o Decreto 2.208/97 (BRASIL, 1997), que regulamentava os artigos sobre a educação profissional na LDB, determinava que a articulação entre ensino médio e educação profissional se restringisse às formas subsequente e concomitante. Nesse sentido, o discurso que vinculava trabalho e educação na LDB foi esvaziado pela supressão da modalidade de ensino integrado.

Apenas com a promulgação do Decreto 5.154 de 2004 (BRASIL, 2004), após troca de governo e de projeto político, é que articulação entre ensino médio e ensino profissional voltou a assumir a forma integrada. Depois dessa sucinta retrospectiva das relações entre ensino médio e educação profissional, o foco da reflexão vai ser direcionado para os aspectos técnicos, pedagógicos e legais da construção de um currículo integrado para o Instituto Federal de Brasília.

\section{A EPT na LDB}

A Lei de Diretrizes e Bases da Educação Nacional (LDB), Lei no 9.394/96, definiu dois níveis escolares para a educação brasileira: a Educação Básica, composta pelas etapas da educação infantil, ensino fundamental e ensino médio; e a Educação Superior, que compreende os cursos de graduação, as licenciaturas, os cursos sequencias, os cursos tecnológicos e a pós-graduação.

Portanto, no contexto da LDB, a educação profissional não faz parte de nenhum nível específico, sendo apresentada como uma modalidade de ensino que pode associarse tanto com a Educação Básica, pelos cursos de Formação Inicial e Continuada e Técnicos de nível médio; quanto com a Educação Superior, nos cursos de Tecnólogos e Licenciaturas.

Modalidades de ensino como a educação profissional, o ensino a distância, a educação indígena e a educação especial são categorias que se relacionam transversalmente com todos os níveis e etapas da educação brasileira, objetivando 


\section{SANTOS (2012)}

garantir o acesso e a permanência do discente que apresenta alguma condição especial: seja a demanda por habilitação profissional (caso da EPT), a localização distante ou a incompatibilidade de horário (EaD), a cultura e língua nativas (educação indígena) e até alguma necessidade específica (PNEs= pessoas com necessidades específicas é uma das nomenclaturas utilizadas para designar os portadores de necessidades especiais, ou deficientes).

O parecer no 7 de 2010 do Conselho Nacional de Educação situa a educação profissional no contexto da educação brasileira:

A Educação Profissional e Tecnológica, no cumprimento dos objetivos da educação nacional, integra-se aos diferentes níveis e modalidades de educação e às dimensões do trabalho, da ciência e da tecnologia, e articula-se com o ensino regular e com outras modalidades educacionais (CNE/CEB, 2010).

Fica evidente que a educação técnica não se restringe apenas a uma qualificação profissional isolada, mas constitui-se como um processo formativo que se articula com o ensino regular, devendo, portanto, cumprir os objetivos legais estabelecidos para os diferentes níveis da educação brasileira.

As considerações sobre a construção de um currículo integrado que conjugue objetivos do ensino médio, como a preparação básica para o trabalho e para o exercício da cidadania, com a formação profissional devem seguir a orientação da LDB, que estabelece: "o ensino médio, atendida a formação geral do educando, poderá prepará-lo para o exercício de profissões técnicas" (LDB, 1996). Ou seja, a educação profissional técnica de nível médio é apresentada como uma alternativa a ser ofertada de maneira complementar à formação geral e básica do discente.

Nesse sentido, na composição de um currículo integrado que articule ensino médio com ensino técnico, a formação para habilitação profissional só poderá ocorrer desde que atendida à formação geral do educando (CNE/CEB, 2004), que é proporcionada pelo caráter propedêutico do ensino médio, etapa final da Educação Básica.

Em outras palavras, no currículo da educação profissional técnica de nível médio na modalidade integrado, os componentes curriculares, competências e habilidades relativas à educação profissional não podem ocupar ou substituir a carga horária e nem as componentes curriculares específicas do ensino médio: "a educação profissional, na LDB, não substitui a educação básica e nem com ela concorre" (CNE/CEB, 1999). Como atesta o Parecer no 39 de 2004 do CNE/CEB "o conteúdo do ensino médio é pré-requisito para a obtenção do diploma de técnico". Outro parecer, o CNE/CEB no 16/99, também reforça que "a preparação básica para o trabalho, no ensino médio, deve incluir as competências que darão suporte para a educação profissional específica".

Para fins de referência, vale registrar que o entendimento de currículo veiculado nesse texto corresponde ao "conjunto de valores e práticas que proporcionam a produção, a socialização de significados no espaço social e contribuem intensamente para a construção de identidades socioculturais dos educandos" (CNE/CEB, 2010).

Posto isso, a elaboração do currículo integrado observa orientações legais como as diretrizes curriculares nacionais para o ensino médio, estabelecidas pelo Conselho Nacional de Educação e pela Câmara de Educação Básica (Resolução CNE/CEB 3/98 e Resolução CNE/CEB 2/2012); as diretrizes curriculares nacionais para a educação profissional técnica de nível médio (Resolução CNE/CEB 4/99, Parecer CNE/CEB 16/99 


\section{SANTOS (2012)}

e Parecer CNE/CEB 11/2012); as normas complementares dos respectivos sistemas de ensino; as exigências de cada instituição de ensino (BRASIL, 2004); e a organização curricular dos cursos técnicos por eixos tecnológicos.

\section{Base nacional comum e diversidade no currículo}

Articulada ao ensino médio na modalidade integrada, a educação técnica deve seguir as orientações da LDB, na qual o currículo da Educação Básica é composto por uma base nacional comum a ser complementada por uma parte diversificada, que deverá considerar e contemplar as diferentes características regionais, econômicas, culturais e sociais do país.

Os conteúdos e competências que compõem a denominada base nacional comum refletem valores fundamentais ao interesse social e à preservação da ordem democrática, que todos os estudantes do ensino médio devem ter acesso, independente da região ou lugar, e que garantem certa unidade às propostas curriculares nacionais (CNE/CEB, 2011). A resolução que define as diretrizes curriculares para a educação básica, CNE/CEB 4/2010, atesta que a base nacional comum origina-se de conhecimentos, saberes e valores produzidos culturalmente, expressos nas políticas públicas e gerados nas instituições produtoras do conhecimento científico e tecnológico, no mundo do trabalho, no desenvolvimento de linguagens, nas atividades desportivas e corporais, na produção artística, nas diversas formas de exercício da cidadania e nos movimentos sociais.

Segundo as Diretrizes Curriculares para o Ensino Médio (CNE/CEB, 2012), a base nacional comum deverá ser organizada em quatro áreas do conhecimento: Linguagens e Códigos, Matemática, Ciências da Natureza e Ciências Humanas. A estrutura curricular dividida em áreas do conhecimento amplas não exclui nem extingue os componentes curriculares com bases epistemológicas próprias, mas favorece a interdisciplinaridade entre eles, com a adoção de objetivos de aprendizagens comuns para a mesma área.

O artigo 26 da LDB especifica alguns componentes curriculares obrigatórios para essas áreas do conhecimento: Língua Portuguesa, Matemática, o mundo físico e natural e a realidade social e política, especialmente brasileira. Além disso, a LDB também determina que Artes (incluindo música como conteúdo exigido, mas não exclusivo) e Educação Física sejam componentes curriculares obrigatórios, e que a História do Brasil estude as matrizes culturais indígenas, africanas e europeias na constituição identitária do povo brasileiro. Já o inciso III do artigo 36 (alterado pela Lei 11.684/2008 (BRASIL, 2008)) da LDB informa que o currículo do ensino médio deve abarcar também conhecimentos em Filosofia e Sociologia, formatados como disciplinas obrigatórias em todas as séries do ensino médio (BRASIL, 2008).

Ainda que elenque algumas disciplinas escolares imprescindíveis à formação básica do discente, a LDB não determina um rol fechado de componentes curriculares oficiais para a base comum nacional, diferentemente da antiga grade curricular fechada e rígida, com disciplinas fixadas pelo Conselho Federal de Educação, como determinava a Lei $\mathrm{n}^{\circ}$ 5.692/71 do regime militar.

Isso significa que não existe um currículo nacional único para o ensino médio, embora a LDB tenha explicitado alguns componentes curriculares e orientações obrigatórias para esta etapa:

Cada escola/rede de ensino pode e deve buscar o diferencial que atenda

EIXO, v 1, n. 1 
as necessidades e características sociais, culturais, econômicas e a diversidade e os variados interesses e expectativas dos estudantes, possibilitando formatos diversos na organização curricular do Ensino Médio, garantindo sempre a simultaneidade das dimensões do trabalho, da ciência, da tecnologia e da cultura. (CNE/CEB, 2011).

Em termos práticos e operacionais, os componentes curriculares obrigatórios decorrentes da LDB que compõe a base nacional comum do ensino médio são: Língua Portuguesa, Matemática, Artes, Educação Física, Biologia, Física, Química, História, Geografia, Filosofia e Sociologia (CNE/CEB, 2012).

Os Parâmetros Curriculares Nacionais (PCNs) [desatualizada: agora são as Diretrizes Curriculares Nacionais] e as Orientações Curriculares para o Ensino Médio da SEB/MEC são considerados referências curriculares nacionais em termos de conteúdos, competências e metodologias a serem desenvolvidos por cada componente curricular.

A parte diversificada do currículo enriquece e complementa a base nacional comum, adequando-se às características políticas, econômicas, culturais e sociais de cada região (CEB/CNE 4/2010). Consta na LDB que a parte diversificada do currículo abrange o estudo indispensável de uma língua estrangeira moderna escolhida pela comunidade. Além disso, a Lei no 11.161/2005 (BRASIL, 2005) inclui a oferta obrigatória, por parte da instituição de ensino, da língua espanhola na parte diversificada do ensino médio, ainda que de matrícula facultativa do aluno. Leis específicas complementam a LDB ao sugerir que temas relativos ao trânsito, ao meio ambiente, aos direitos humanos, a educação alimentar e nutricional e à condição e direitos do idoso (CNE/CEB 4/2010) estejam presentes em todos os níveis e modalidades do processo educativo. Esses componentes curriculares, instituídos por lei, podem ser incluídos na parte diversificada do currículo do ensino médio sem, necessariamente, constituírem disciplinas escolares específicas.

Além das indicações legais, outros componentes curriculares poderiam constituir a parte diversificada do currículo de ensino médio do IFB como temas e noções relativos ao direito constitucional, já que, o conhecimento sobre a Carta Magna é premissa essencial para o exercício da cidadania crítica e consciente, além do PAS (Programa de Avaliação Seriada da Universidade de Brasília) ter instituído como objeto de avaliação os artigos $5^{\circ}$ ao $11^{\circ}, 14^{\circ}$ ao $17^{\circ}$ e $44^{\circ}$ ao $56^{\circ}$ da atual Constituição Federal do Brasil (BRASIL, 1988). A componente "Noções de Direito Constitucional" seria conduzida pelos docentes da área de humanas (história, sociologia ou filosofia). Também poderia integrar a parte diversificada, conhecimentos em informática, tão relevantes em mundo onde a informação circula quase que instantaneamente e os serviços estão todos informatizados. A possibilidade de utilização de uma atividade lúdica mas revestida de caráter pedagógico, como o jogo de xadrez, proporcionaria o desenvolvimento cognitivo, o raciocínio lógico, a concentração e a autonomia na tomada de decisões dos estudantes.

Por fim, a parte diversificada pode ser ocupada por um projeto integrador, cuja proposta será detalhada no item 6.

\section{A carga horária do curso integrado}

$\mathrm{Na}$ questão da carga horária do ensino médio, o artigo 24 da LDB estipulou o mínimo de 800 horas (horas relógio de 60 minutos, e não a hora/aula de 50 minutos) anuais distribuídas em, pelo menos, 200 dias letivos, excluídos os dias destinados aos 


\section{SANTOS (2012)}

exames finais. Este mesmo documento fixou a duração mínima do ensino médio regular em 3 anos, fato que totaliza a carga horária mínima reservada ao triênio do segmento médio em 2.400 horas.

Segundo as Diretrizes Curriculares para o Ensino Médio de 1998 (CNE/CEB 3/98), a base nacional comum deverá ocupar pelo menos $75 \%$ das 2.400 horas estabelecidas como carga horária mínima para o ensino médio, o que equivale a 1.800 horas. As 600 horas restantes poderão ser complementadas pelos componentes da parte diversificada, como os projetos integradores. Mesmo na modalidade integrada, é vedada a inclusão de componentes curriculares relativos ao curso técnico na parte diversificada do currículo do ensino médio, correspondente a $25 \%$ da carga horária deste segmento.

O Catálogo Nacional de Cursos Técnicos do MEC estabeleceu a quantidade mínima de horas necessárias para a conclusão de cada habilitação profissional, que variam entre $800,1.000$ ou 1.200 horas.

A integração entre o ensino médio e o ensino técnico implica uma ampliação da carga horária total do curso de ensino médio de modo a garantir, simultaneamente, os objetivos estabelecidos tanto para a formação geral, quanto para o exercício de profissões técnicas. Teoricamente, a carga horária mínima do ensino médio de 2.400 horas deveria ser adicionada à carga horária mínima do curso técnico, que varia entre $800,1.000$ ou 1.200 horas. Ou seja, dependendo da habilitação profissional selecionada, os cursos técnicos integrados ao ensino médio poderiam ter cargas horárias mínimas de 3.200 , 3.400 ou 3.600 horas. Sendo assim, na modalidade integrada, o ensino profissional técnico de nível médio pode ter duração superior a três anos.

Mas, idealmente, o curso integrado não é a somatória ou sobreposição de dois cursos diferentes, um técnico mais outro de ensino médio (esse é o conceito do concomitante), mas a síntese entre os dois cursos, que se transformam em um curso único, condensado, com projeto pedagógico único, currículo único e matrícula única. [poderia o artigo provocar essa discussão]

Já que a intenção é mesclar os cursos "(...) esse novo arranjo curricular pode possibilitar uma economia na carga horária mínima exigida, uma vez que o desenvolvimento de competências cognitivas e profissionais pode ser facilitado, exatamente por essa integração curricular" (CNE/CEB 39/2004). Embora a educação profissional técnica tenha seus princípios específicos (competências para laborabilidade, flexibilidade, interdisciplinaridade, contextualização, identidade dos perfis profissionais, atualização permanente dos cursos e currículos, e autonomia da escola em seu projeto pedagógico), que devem nortear sua organização curricular, ela compartilha com 0 ensino médio princípios, como a estética da sensibilidade, a política da igualdade e a ética da identidade (CNE/CEB 16/99).

Sintonizado com essa perspectiva está o artigo 5ำ da Resolução CEB/CNE de 1/2005, que instituiu a carga horária total mínima dos cursos de educação profissional técnica integrada ao ensino médio em 3.000 horas para as habilitações profissionais que exigem o mínimo de 800 horas, em 3.100 horas para as habilitações profissionais que demandam o mínimo de 1.000 horas e em 3.200 horas para aquelas que exigem o mínimo de 1.200 horas. Deve-se realçar que a carga horária destinada ao estágio supervisionado $(\mathrm{CEB}, 99)$ deverá ser acrescentada à carga horária mínima exigida para a habilitação profissional integrada ao ensino médio.

No caso do ensino médio integrado, um curso com 3.000 horas iria durar mais do que três anos, o que poderia contribuir para evasão escolar. Mas existe a possibilidade da oferta do ensino médio integrado e integral (o estudante passa o dia inteiro na escola), com duração mínima de sete horas diárias (CNE/CEB 2/2012). Desse modo os cursos 


\section{SANTOS (2012)}

integrados poderiam durar os três anos tradicionais do ensino médio. No caso do integral, a limitação para os alunos seria a necessidade de conciliar trabalho e estudo, imperativo comum nas comunidades carentes que dispõem de um Campus do IFB.

Consultas à Coordenação Geral de Ensino Médio do MEC, à SETEC e à SEDF indicaram que não existe legislação federal determinando a carga horária mínima das componentes curriculares obrigatórias da base nacional comum do ensino médio. A LDB estabelece como atribuição dos estados e do DF "assegurar o ensino fundamental e oferecer, com prioridade, o ensino médio". É por essa razão que as secretarias de educação dos entes federativos estaduais e distritais têm liberdade para organizar e elaborar sua matriz curricular, distribuindo cargas horárias diferentes para as componentes curriculares obrigatórias. Como o IFB é uma instituição federal, a distribuição da carga horária ainda necessita ser formulada.

No contexto do ensino técnico, a tendência, ou tentação, é a ampliação da carga horária das áreas do conhecimento Matemática e Ciências da Natureza, mas "(...) a incorporação das ciências humanas na formação do trabalhador é fundamental para garantir o currículo integrado" (CNE/CEB, 5/2011).

Internamente, a Resolução 23/2009 do IFB definiu a duração do semestre letivo dos campi no DF com o mínimo de 20 semanas letivas, ressalvados os 200 dias letivos anuais exigidos pela LDB. Já a Resolução do IFB 21/2012 determina que a carga horária total de cada curso não exceda $15 \%$ do mínimo previsto na legislação.

As Diretrizes Curriculares para Educação Profissional Técnica de nível médio de 2012 permitem que os planos de curso prevejam atividades não presenciais em até $20 \%$ da carga horária diária do curso, desde que haja recursos humanos suficientes, docentes e tutores, e aparato tecnológico adequado. Essa possibilidade pode se transformar em um recurso importante na medida em que contribui para manutenção dos alunos trabalhadores na instituição de ensino.

\section{Conclusão: uma proposta integradora}

A apresentação de uma proposta de integração curricular entre os conteúdos dos cursos técnicos e o ensino médio não pretende ser definitiva, nem formalizar conclusões precipitadas, pelo contrário, objetiva contribuir para reflexão e debate de uma estratégia de integração a ser desenvolvida por cada Campus, adequando-se às suas peculiaridades e interesses.

O curso integrado deve ser concebido como um curso único, uma síntese, uma amálgama, entre o curso técnico e o ensino médio. Nesse sentido, a integração deve estar presente em todo currículo e durante todo período letivo, envolvendo o maior número de componentes curriculares possíveis. A proposta visa construir a integração conciliando duas ferramentas já empregadas no campo pedagógico: eixos integradores e projetos integradores.

Eixos integradores são noções, conceitos ou princípios que devem ser abordados por todas as disciplinas em um período letivo estipulado (um mês, um bimestre, um semestre). $\mathrm{O}$ eixo integrador pode ser entendido como um objeto de estudo comum, algo que seja significativo para a comunidade escolar e que será trabalhado por todas as componentes curriculares, básicas e técnicas. De certa forma, todas as disciplinas orbitariam em torno dos eixos.

A ideia do eixo integrador é fundamentada em categorias consolidadas na área educacional: interdisciplinaridade e transversalidade. Para fins de comparação, o 


\section{SANTOS (2012)}

conceito de eixo integrador aproxima-se do tema gerador de Paulo Freire ou dos temas transversais veiculados nos Parâmetros Curriculares Nacionais. [?]

Atualmente, os conhecimentos são organizados com base na multidisciplinaridade: os conteúdos são apresentados em disciplinas independentes, que não estabelecem relações entre as informações ou métodos do currículo. Já o eixo integrador segue a noção de que "A interdisciplinaridade pressupõe a integração entre os conteúdos e as metodologias de disciplinas diferentes que se propõe a trabalhar conjuntamente determinados temas." (FONSECA, 2003).

O eixo integrador proporciona uma compreensão mais completa e holística do conceito ou princípio proposto como eixo. Na complexidade do real, os fenômenos produtivos possuem múltiplas dimensões e a análise do mesmo objeto por várias perspectivas facilita a percepção dos vínculos e relações entre as disciplinas. Essa visão multifacetada do eixo seria aplicada e operacionalizada nos projetos integradores.

Tão importante quanto a adoção metodológica dos eixos integradores é a definição dos eixos que comporão o curso. A eleição dos eixos deve ser feita em conjunto, em reuniões entre os coordenadores das áreas de conhecimento do ensino médio e o coordenador da parte técnica. Essa equipe de coordenadores articularia 0 processo de integração planejando, deliberando e definindo orientações para integração dentro de sua área de conhecimento, além de responsabilizar-se pela condução dos projetos integradores.

A legislação contribui para definição dos eixos integradores, já que as Diretrizes Curriculares do Ensino Médio estabelecem "as dimensões do trabalho, da ciência e da tecnologia e da cultura como eixo integrador entre os conhecimentos de distintas naturezas" (CNE/CEB 2/2012). No contexto do ensino médio integrado, as dimensões da ciência e tecnologia poderiam ser as bases tecnológicas das disciplinas técnicas, e as dimensões da cultura e do trabalho poderiam abrigar questões significativas para a comunidade na qual está inserida a instituição escolar.

Vamos tomar como exemplo um curso integrado em Química. Os eixos integradores poderiam ser algumas das bases tecnológicas da parte técnica: átomos; energia; processos; modelos; estruturas; química orgânica; carbono; corrosão; radiação; micro-organismos; minerais; metais; gases; unidades de medidas; indústrias e laboratórios; combustíveis; a matéria e seus estados físicos; fenômenos físico-químicos; produtos de higiene e cosméticos; produtos alimentícios; agrotóxicos; dentre outros.

Mas os eixos integradores também deveriam abarcar dimensões da cultura e do trabalho que fossem relevantes para comunidade escolar, tais como: eleições; tratamento de resíduos e reciclagem; acúmulo de águas; pobreza; trânsito; meio ambiente; turismo; lixo e poluição; empreendedorismo; cooperativismo; saúde e segurança no trabalho; corpo humano; ética; entorpecentes; olimpíadas; televisão e outras mídias; trabalho e desemprego; patrimônio; cidadania.

$\mathrm{Na}$ prática, os eixos integradores seriam desenvolvidos durante as aulas regulares do currículo. Trabalhar com o eixo integrador não significa que os docentes teriam que replanejar todas as aulas ou abordar apenas o eixo integrador em sua disciplina, mas reservar momentos, dentro do período estipulado, para salientar as relações entre o seu conteúdo e o eixo integrador. Recordo [?] que, de acordo com o art. 36-A da LDB, a formação geral tem prioridade sobre a formação técnica. Desse modo, os professores ministrariam seus conteúdos normalmente, mas introduziriam exposições orais e atividades que contemplassem os vínculos da sua matéria com o eixo integrador. 0 processo de integração entre os cursos seria construído gradativamente durante 0 cotidiano das aulas e contaria com a realização de reuniões periódicas entre os docentes 


\section{SANTOS (2012)}

das componentes técnicas e básicas para ir ajustando e aperfeiçoando a integração.

As disciplinas da área de linguagens poderiam trabalhar com textos instrumentais, que contivessem os jargões da área técnica, ou abordar as diversas expressões e linguagens que representassem o eixo integrador. A área de humanas poderia examinar a história, filosofia ou sociologia da ciência, contextualizando e analisando o desenvolvimento do conhecimento como construção histórica, inacabada. No caso do curso integrado em Química, a área de humanas poderia subsidiar a compreensão dos contextos que propiciaram a elaboração das teorias de Demócrito ou Dalton e refletir sobre as dimensões políticas, sociais e históricas de fenômenos relacionados à Química, como a mineração em Minas Gerais, a bomba atômica na II Guerra Mundial, a alquimia medieval ou o césio 137 de Goiânia.

Para consolidar a estratégia de integração do curso técnico com o ensino médio, os eixos integradores estudados por todas as componentes curriculares em determinado período letivo devem ser articulados ao projeto integrador. O conceito de projeto integrador está detalhado nos "Protótipos Curriculares de Ensino Médio e Ensino Médio Integrado: resumo executivo", da UNESCO (2011).

O projeto integrador é uma componente curricular específica que cria condições tanto para o desenvolvimento de competências laborais, baseadas no perfil profissional do egresso do curso, quanto para a aplicação dos eixos integradores em situações mais concretas da prática profissional. O Regulamento do Ensino Técnico do IFB estabelece que "Os componentes curriculares devem colaborar entre si com a construção do perfil do egresso de cada curso, possibilitando a realização de avaliações e/ou projetos integradores envolvendo mais de um componente curricular.".

O projeto integrador oportuniza a problematização dos eixos integradores em procedimentos relativos à rotina profissional de um técnico. Nesse sentido, os eixos integradores figuram como temas ou "problemas" em atividades que concretizam o projeto integrador: a elaboração de laudos e perícias, a formulação de um plano de trabalho, a interpretação e análise de resultados, a execução de técnicas operacionais específicas, a identificação de parâmetros, estudos de caso, a seleção de métodos, a coleta de dados e o manuseio de equipamentos.

Que tipo de atividade enfatizar no projeto integrador? Uma consulta ao Plano de Curso revela o perfil desejado para o egresso e o rol de competências que ele terá que aprimorar: ter capacidade gerencial de adaptar-se a novas situações, ter boa comunicação oral e escrita, compreender as bases tecnológicas do curso, supervisionar processos, atualizar-se com relação a novas tecnologias, manter postura ética e profissional, realizar análises, padronizar métodos, operar e realizar a manutenção de equipamentos, identificar oportunidades, avaliar custos, desenvolver pesquisas na área e etc. $O$ projeto integrador também pode favorecer o desenvolvimento de competências laborais gerais como planejamento, trabalho em equipe, liderança, flexibilidade, capacidade de iniciativa, relacionamento interpessoal, habilidade para negociar, criatividade, delegação de tarefas e disciplina.

De preferência, o projeto integrador deverá ter uma dimensão prática, sendo ambientado no mundo do trabalho e materializado em proposições de problemas organizacionais. Adotando a pesquisa como princípio pedagógico, o projeto integrador permite que o discente seja protagonista na construção de sua aprendizagem, ao contrário do papel de expectador de aulas expositivas. O projeto integrador enseja a intervenção do aluno na realidade do seu trabalho ou da sua comunidade, sugerindo soluções, melhorando o processo produtivo e recomendando melhorias nas gestões e operações. Por fim, os resultados dos projetos integradores poderiam ser compartilhados 


\section{SANTOS (2012)}

em espaços como feiras de ciência ou cultura da instituição, e até registrados como patentes industriais.

Os responsáveis pelo projeto integrador seriam os coordenadores das quatro áreas de conhecimento e o coordenador do curso técnico, que, durante as reuniões, avaliariam o curso, estabeleceriam estratégias de integração e proporiam aprimoramentos pedagógicos. O projeto integrador ocuparia a carga horária da parte diversificada do currículo dispondo de até 200 horas anuais para cumprir os seus objetivos.

A proposta de integração apresentada neste breve ensaio não representa um ponto final, mas um ponto de partida, pois pretende gerar críticas e debates que contribuam para a construção da integração adaptada à realidade de cada Campus.

\section{Referências}

BRASIL. Constituição (1937). Diário Oficial, Rio de Janeiro, RJ, 10 nov. 1937. Disponível em: <http://www.planalto.gov.br/ccivil_03/constituicao/constituiçao37.htm>. Acesso em: 11 nov. 2011.

BRASIL. Constituição (1988). Diário Oficial [da] República Federativa do Brasil, Brasília, DF, 5 out. 1988. Disponível em:

https://www.planalto.gov.br/ccivil_03/constituicao/constituicao.htm. Acesso em: 11 nov. 2011.

BRASIL. Lei 5.692, de 11 de agosto de 1971. Fixa diretrizes e bases para o ensino de $1^{\circ}$ e $2^{\circ}$ graus, e dá outras providências. Diário Oficial [da] República Federativa do Brasil, Brasília, DF, 12 ago. 1971. Disponível em: <http://www.planalto.gov.br/ccivil_03/leis/L5692.htm>. Acesso em: 20 de jan. 2011.

BRASIL. Lei 7.044, de 18 de outubro de 1982. Altera dispositivos da lei 5. 692, de 11 de agosto de 1971, referentes a profissionalização do ensino de $2^{\circ}$ grau. Diário Oficial [da] República Federativa do Brasil, Brasília, DF, 19 out. 1982. Disponível em: <http://www.planalto.gov.br/ccivil_03/leis/L7044.htm>. Acesso em: 20 jan. 2011.

BRASIL. Lei no 9.394, de 20 de dezembro de 1996. Estabelece as diretrizes e bases da educação nacional. Diário Oficial [da] República Federativa do Brasil, Brasília, DF, 23 dez. 1996. Disponível em: <http://www.planalto.gov.br/ccivil_03/leis/L9394.htm>. Acesso em: 03 fev. 2011.

BRASIL. Lei nำ 9.475, de 22 de julho de 1997. Dá nova redação ao art. 33 da Lei 9.394, de 20 de dezembro de 1996, que estabelece as diretrizes e bases da educação nacional. Diário Oficial [da] República Federativa do Brasil, Brasília, DF, 23 jul. 1997. Disponível em: < http://www.planalto.gov.br/ccivil_03/leis/L9475.htm>. Acesso em: 03 fev. 2011.

BRASIL. Lei no 9.503, de 23 de setembro de 1997. Institui o Código Brasileiro de Trânsito. Diário Oficial [da] República Federativa do Brasil, Brasília, DF, 24 set. 1997. Disponível em: < http://www.planalto.gov.br/ccivil_03/leis/L9503.htm>. Acesso em: 14 fev. 2011. 


\section{SANTOS (2012)}

BRASIL. Lei no 9.795, de 27 de abril de 1999. Dispõe sobre a Educação Ambiental. Diário Oficial [da] República Federativa do Brasil, Brasília, DF, 28 abr. 1999. Disponível em: < http://www.planalto.gov.br/ccivil_03/Leis/L9795.htm>. Acesso em: 20 fev. 2011.

BRASIL. Lei no 10.741 , de $1^{\circ}$ de outubro de 2003. Dispõe sobre o estatuto do idoso. Diário Oficial [da] República Federativa do Brasil, Brasília, DF, 3 out. 2003. Disponível em: < http://www.planalto.gov.br/ccivil_03/leis/2003/L10.741.htm>. Acesso em: 13 fev. 2011.

BRASIL. Lei no 11.161, de 5 de agosto de 2005. Dispõe sobre o ensino de língua espanhola. Diário Oficial [da] República Federativa do Brasil, Brasília, DF, 8 ago. 2005. Disponível em <http://www.planalto.gov.br/ccivil_03/_Ato20042006/2005/Lei/L11161.htm>. Acesso em: 21 fev. 2011.

BRASIL. Lei oㅜ 11.684, de 2 de junho de 2008. Altera o art. 36 da Lei no 9.394, de 20 de dezembro de 1996. Estabelece as diretrizes e bases da educação nacional, para incluir a Filosofia e a Sociologia como disciplinas obrigatórias nos currículos do ensino médio. Diário Oficial [da] República Federativa do Brasil, Brasília, DF, 3 jun. 2008. Disponível em <http://www.planalto.gov.br/ccivil_03/_Ato2007-2010/2008/Lei/L11684.htm>. Acesso em: 14 nov. 2011.

BRASIL. Lei no 11.947, de 16 de junho de 2009. Dispõe sobre o atendimento da alimentação escolar. Diário Oficial [da] República Federativa do Brasil, Brasília, DF, 17 jun. 2009. Disponível em: < http://www.planalto.gov.br/ccivil_03/_ato20072010/2009/lei/l11947.htm>. Acesso em: 07 nov. 2011.

BRASIL. Decreto 2.208, de 17 de abril de 1997. Regulamenta o $\S 2^{\circ}$ do art. 36 e os arts. 39 a 42 da Lei 9394, de 20/12/1996, que estabelece as diretrizes e bases da educacao nacional. Diário Oficial [da] República Federativa do Brasil, Brasília, DF, 18 abr. 1997. Disponível em: <http://www.planalto.gov.br/ccivil_03/decreto/D2208.htm>. Acesso em: 15 nov. 2011.

BRASIL. Decreto 5.154, de 23 de julho de 2004. Regulamenta o $\S 2^{\circ}$ do art. 36 e os arts. 39 a 41 da Lei no 9.394, de 20 de dezembro de 1996. Estabelece as diretrizes e bases da educação nacional, e dá outras providências. Disponível em: <http://www.planalto.gov.br/ccivil_03/_ato2004-2006/2004/decreto/d5154.htm>. Acesso em: 22 nov. 2011.

BRASIL. Decreto no 7.037, de 21 de dezembro de 2009. Aprova o programa nacional de direitos humanos - PNDH-3 e dá outras providências. Diário Oficial [da] República Federativa do Brasil, Brasília, DF, 22 dez. 2009. Disponível em: <http://www.planalto.gov.br/ccivil_03/_Ato2007-2010/2009/Decreto/D7037.htm>. Acesso em: 01 dez. 2011.

BRASIL. Ministério da Educação. Resolução CNE/CEB no 04, de 03 de dezembro de 1999. Institui as Diretrizes Curriculares Nacionais para a Educação Profissional de Nível Técnico. Disponível em:

$<$ http://portal.mec.gov.br/setec/arquivos/pdf_legislacao/tecnico/legisla_tecnico_resol0499.

EIXO, v 1, n. 1 


\section{SANTOS (2012)}

pdf>. Acesso em: 13 dez. 2011.

Resolução CNE/CEB no 3, de 26 de junho de 1998. Institui as

Diretrizes Curriculares Nacionais para o Ensino Médio. Disponível em:

<http://portal.mec.gov.br/cne/arquivos/pdf/rceb03_98.pdf>. Acesso em: 17 dez. 2011.

Parecer CNE/CEB no 11, de 12 de junho de 2008. Proposta de instituição do Catálogo Nacional de Cursos Técnicos de Nível Médio. Disponível em: <http://portal.mec.gov.br/setec/arquivos/pdf/pceb011_08.pdf>. Acesso em: 03 mar. 2011.

Parecer CNE/CEB no 2, de 23 de janeiro de 2012. Define Diretrizes Curriculares Nacionais para o Ensino Médio. Disponível em: < http://portal.mec.gov.br/index.php?option=com_content\&view=article\&id=17417\&ltemid=8 66>. Acesso em: 09 mar. 2011.

Resolução CNE no 1, de 17 de junho de 2004. Institui Diretrizes Curriculares Nacionais para a Educação das Relações Étnico-Raciais e para o Ensino de História e Cultura Afro-Brasileira e Africana. Disponível em: <http://portal.mec.gov.br/cne/arquivos/pdf/res012004.pdf> Acesso em: 19 mar. 2011.

Resolução CNE/CEB no 4, de 13 de julho de 2010. Define as Diretrizes Curriculares Nacionais para a Educação Básica. Disponível em: < http://portal.mec.gov.br/index.php?ltemid=866\&id=14906\&option=com_content\&view=arti cle>. Acesso em: 20 mar. 2011.

Parecer CNE/CEB no 16/99. Trata das Diretrizes Curriculares Nacionais para a Educação Profissional de Nível Técnico. Disponível em: < http://portal.mec.gov.br/setec/arquivos/pdf_legislacao/tecnico/legisla_tecnico_parecer169 9.pdf>. Acesso em: 25 mar. 2011.

Parecer CNE/CEB no 39/2004. Aplicação do Decreto no 5.154/2004 na Educação Profissional Técnica de nível médio. Disponível em: < http://portal.mec.gov.br/setec/arquivos/pdf_legislacao/tecnico/legisla_tecnico_parecer392 004.pdf>. Acesso em: 07 abr. 2011.

Parecer CNE/CEB no 7/ 2010. Diretrizes Curriculares

Nacionais Gerais para a Educação Básica. Disponível em: < http://portal.mec.gov.br/index.php?option=com_content\&view=article\&id=12992>. Acesso em: 09 abr. 2011.

Parecer CNE/CEB nำ 5/2011. Diretrizes Curriculares

Nacionais para o Ensino Médio. Disponível em: <

http://portal.mec.gov.br/index.php?option=com_content\&view=article\&id=16368\&ltemid=8 66>. Acesso em: 17 abr. 2011.

Resolução no 21-2012/CS-IFB. Aprova o Regimento Geral do Instituto Federal de Brasília- IFB. Disponível em: < http://www.ifb.edu.br/attachments/2939_Resolu\%C3\%A7\%C3\%A30\%20RIFB_012_2012EIXO, v 1 , n. 1 


\section{SANTOS (2012)}

Aprova\%20Regimento\%20Geral\%20do\%20IFB.pdf>. Acesso em: 17 abr. 2011.

Resolução no 14-2012/CS-IFB. Regulamento do Ensino

Técnico de Nível Médio do Instituto Federal de Brasília. Disponível em: < http://www.ifb.edu.br/attachments/2939_Resolu\%C3\%A7\%C3\%A30\%20RIFB_014_2012 Regulamenta\%200\%20\%20Ensino\%20Te\%CC\%81cnico\%20de\%20Ni\%CC\%81vel\%20 Me\%CC\%81dio\%20no\%20IFB.pdf> . Acesso em: 14 abr. 2011.

Documento Base/ dez. 2007. Educação Profissional Técnica de Nível Médio integrada ao ensino médio. Brasília. Disponível em: < http://portal.mec.gov.br/setec/arquivos/pdf/documento_base.pdf>. Acesso em: 15 abr. 2011.

Catálogo Nacional dos Cursos Técnicos/ 2012. Disponível em: < http://pronatec.mec.gov.br/cnct/>. Acesso em: 18 abr. 2011.

FONSECA, Selva. Didática e prática do ensino de história: experiências, reflexões e aprendizados. Campinas: Papirus, 2003.

SANTOS, Clóvis Roberto dos. Direito à educação: a LDB de A a Z. São Paulo: Avercamp, 2008.

SAVIANI, Dermeval. A pedagogia no Brasil: história e teoria. Campinas: Autores Associados, 2008.

UNESCO. Protótipos Curriculares de Ensino Médio e Ensino Médio Integrado: resumo executivo. Série Debates ED, № 1, mai. 2011. Disponível em: < http://unesdoc.unesco.org/images/0019/001922/192271POR.pdf>. Acesso em: 05 mai. 2011. 